\title{
KAJIAN SAINTIFIKASI BAHAN KONSERVASI TRADISIONAL BERDASARKAN NASKAH KUNA
}

\author{
Isni Wahyuningsih, Henny Kusumawati, Yudi Atmaja, Al Widyo Purwoko, \\ Ari Kristivanto \\ Balai Konservasi Borobudur \\ isni.wahyuningsih@gmail.com
}

\begin{abstract}
ABSTRAK
Naskah-naskah kuna masih banyak dijumpai di Nusantara. Di dalam naskah kuna tersebut antara lain memuat pengetahuan tentang praktek-praktek konservasi yang hingga sekarang masih dilakukan masyarakat. Pada Kajian Bahan Konservasi Tradisional Berdasarkan Naskah Kuna pada tahun 2016 - 2018, ditemukan beberapa muatan mengandung aktivitas konservasi tradisional yang mewakili kearifan lokal masyarakat Jawa, Bali dan Sumatra. Sementara itu untuk kajian saintifikasi dipilih sampel untuk bahan konservan yang terdapat dalam naskah kuna yaitu daun sirih (piper betle), biji dan daun bidara (ziziper mauritania).

Berdasarkan hasil uji aplikasi minyak daun dan biji bidara (ziziper mauritania) yang diujikan pada serangga (rayap) dengan konsentrasi $0.5 \%, 1 \%$, 3\%, 5\% tidak menunjukkan fungsi sebagai bahan konservan anti serangga. Sementara itu minyak daun sirih (piper betle) yang diujikan pada serangga (rayap) dengan konsentrasi $0.5 \%, 1 \%, 3 \%, 5 \%$ menunjukkan bahwa tingkat mortalitas serangga (rayap) pada konsentrasi $0.5 \%$ - 3\% tingkat mortalitas 60 - 90 \%, dan serangga pada konsentrasi $5 \%$ tingkat mortalitas $100 \%$. Berdasarkan hasil uji tersebut dapat disimpulkan minyak sirih dapat menjadi bahan alternatif konservan anti serangga (rayap).
\end{abstract}

Kata kunci: Konservasi tradisonal, naskah kuna, daun sirih (piper betle), daun bidara (ziziper mauritania), bahan alternatif, anti serangga (rayap).

\section{ABSTRACT}

Ancient manuscripts are still widely found in the archipelago. The ancient manuscript contains knowledge about conservation practices that are still being practiced by the community. In the Study of Traditional Conservation Materials Based on Old Manuscripts in 2016-2018, it was found contained traditional conservation activities that represented the local wisdom of the Javanese, Balinese and Sumatran people. Meanwhile, for the scientific study, samples were selected for the conservant material contained in ancient texts, namely betel leaf (piper betle) and bidara leaf (ziziper mauritania).

Based on the test results of the application of bidara leaf and seed oil (ziziper Mauritania) tested on insects (termites) with a concentration of $0.5 \%, 1 \%, 3 \%, 5 \%$, it does not show a function as an insect-resistant conservant. Meanwhile, piper betle oil tested on insects (termites) with a concentration of $0.5 \%, 1 \%, 3 \%, 5 \%$ shows that the mortality rate for insects (termites) at a concentration of $0.5 \%-3 \%$ is $40 \%-70 \%$ mortality rate and insects at a concentration of $5 \%$ mortality rate of $100 \%$. Based on the results of these tests, it can be concluded that betel oil can be an alternative ingredient for insect repellent conservants (termites).

Key words: Traditional conservation, ancient manuscripts, betel leaf (piper betle), bidara leaf (ziziper Mauritania), alternative materials, insect repellent (termites). 


\section{PENDAHULUAN}

Praktek konservasi tradisional sampai sekarang masih ada di masyarakat, meskipun di era ini berkembang praktek-praktek konservasi modern yang cenderung menggunakan bahan kimiawi. Konservasi tradisional dapat kita ketahui secara lisan secara turun temurun (folklor) maupun tulisan yang dimuat dalam naskah-naskah kuna. Naskah kuna juga sebagai bukti hasil kegiatan intelektual masyarakat tradisional di masa lampau dalam memecahkan permasalahan dalam kehidupan (local genius) antara lain dalam hal konservasi (Susena, 2013; Kasrina, 2015).

Indonesia kaya akan khazanah warisan budaya tertulis dalam bentuk naskah (manuskrip) yang berjumlah ribuan yang tersimpan di dalam negeri maupun di luar negeri, dimiliki oleh pemerintah maupun milik pribadi. Naskah-naskah tersebut merupakan hasil karya para pujangga kerajaan-kerajaan, bangsawan, golongan tertentu, ataupun masyarakat adat (Sarwit, 2000).

Pada Kajian Konservasi Tradisional Berdasarkan Naskah Kuna pada tahun 2017 2018, ditemukan beberapa muatan mengandung aktivitas konservasi tradisional. Data konservasi tradisional berdasarkan naskah kuna yang telah terkumpul pada kajian sebelumnya, yang mewakili kearifan lokal masyarakat Jawa, Bali dan Sumatra mengenai konservasi yang termuat dalam naskah kuna dan dipilih sebagai sampel uji.

Tabel 1. Bahan konservan yang termuat dalam naskah kuna

\begin{tabular}{|c|c|c|c|c|}
\hline No & Kearifan Lokal & Bahan Konservan & Metode & $\begin{array}{l}\text { Manfaat untuk } \\
\text { konservasi }\end{array}$ \\
\hline \multirow[t]{3}{*}{1} & \multirow{3}{*}{$\begin{array}{l}\text { Jawa } \\
\text { (Sumber: Serat } \\
\text { Centhini, Serat } \\
\text { Kawruh } \\
\text { Tetuwuhan, } \\
\text { Serat, Serat } \\
\text { Kawruh Kalang) }\end{array}$} & $\begin{array}{c}\text { Daun } \\
\text { Rembaga/Widura/Bidara }\end{array}$ & Ditumbuk & $\begin{array}{l}\text { Membasmi ulat } \\
\text { /kutu/serangga }\end{array}$ \\
\hline & & Minyak Letung & Dioles/disemprot & $\begin{array}{l}\text { Membasmi ulat, } \\
\text { serangga, kutu }\end{array}$ \\
\hline & & $\begin{array}{l}\text { Kayu untuk bahan } \\
\text { bangunan }\end{array}$ & $\begin{array}{c}\text { Pemilihan kayu } \\
\text { waktu/lokasi/kondisi } \\
\text { tanah/proses/tatacara } \\
\text { penebangan serta } \\
\text { perlakuan setalah } \\
\text { penebangan }\end{array}$ & $\begin{array}{l}\text { Mendapatkan kayu } \\
\text { berkualitas bagus/ } \\
\text { awet/tahan } \\
\text { lama/tahan rayap }\end{array}$ \\
\hline \multirow[t]{3}{*}{2} & $\begin{array}{l}\text { Bali } \\
\text { (Sumber: }\end{array}$ & & Dibakar/dioles & $\begin{array}{l}\text { Menajamkan tulisan } \\
\text { mengawetkan lontar }\end{array}$ \\
\hline & $\begin{array}{l}\text { wawancara } \\
\text { dengan warga } \\
\text { di pemilik }\end{array}$ & $\begin{array}{l}\text { Kunyit, lada, pala, cabe, } \\
\text { cengkeh }\end{array}$ & $\begin{array}{l}\text { Direbus bersama } \\
\text { lontar pada proses } \\
\text { pembuatan }\end{array}$ & $\begin{array}{l}\text { Membuat lontar awet } \\
\text { dari serangan rayap, } \\
\text { jamur, serangga }\end{array}$ \\
\hline & $\begin{array}{l}\text { naskah } \\
\text { Sidemen, Bali) }\end{array}$ & Lengkuas & Dioles & $\begin{array}{l}\text { Untuk mengobati } \\
\text { penyakit jamur }\end{array}$ \\
\hline \multirow[t]{3}{*}{3} & $\begin{array}{l}\text { Sumatra } \\
\text { (Sumber: }\end{array}$ & Sirih & Dibakar & $\begin{array}{c}\text { Mengusir/membasmi } \\
\text { lebah/serangga }\end{array}$ \\
\hline & $\begin{array}{l}\text { Naskah Ka Ga } \\
\text { Nqa di Museum }\end{array}$ & Kemiri, nangka, kandis & Ditumbuk, Dioles & $\begin{array}{c}\text { Mengobati penyakit } \\
\text { karena jamur }\end{array}$ \\
\hline & Bengkulu) & Air rendaman beras & Disemprot & Mengusir ulat \\
\hline
\end{tabular}

Bahan ataupun metode konservasi tersebut diharapkan dapat diaplikasikan pada cagar budaya, setelah melalui uji ilmiah (saintifikasi) melalui percobaan dan pengujian di laboratorium.

Adapun tujuan dari kajian tersebut adalah mengetahui keilmiahan bahan konservasi tradisional yang dahulu dilakukan oleh nenek moyang yang dimuat dalam 
naskah-naskah kuna, dan harapannya setelah melalui uji ilmiah bahan tersebut dapat dimanfaatkan sebagai bahan alternatif konservasi cagar budaya.

\section{METODE \\ Alat dan Bahan}

Alat dan bahan yang dipakai dalam percobaan laboratoium dan lapangan adalah alat tulis, kertas, pinset, pipet, kamera, kertas label, botol kecil, gunting, sarung tangan, batang pengaduk, timbangan, ketel penyuling, cawan petri, LAF (Laminar Air Flow).

Bahan : Minyak atsiri sirih, daun sirih, daun bidara, biji buah bidara, rayap kayu kering, gelas plastik, kertas whatman, medium CDA (Czapex Dox Agar)

\section{Tempat Riset}

Pengujian laboratorium di laboratorium UII di Yogyakarta dilakukan pada ekstrak daun sirih/minyak Sirih, daun bidara, minyak biji buah Bidara dan hidrosol bidara. Sementara itu untuk uji implementasi dilakukan di laboratorium Balai Konservasi Borobudur.

\section{Cara Kerja}

Langkah ataupun tahapan yang dilakukan dalam kajian ini adalah pemilihan bahan konservan yang telah dipilih untuk diuji sebagai anti serangga (rayap), diawali dengan pembuatan ekstrak atau minyak sirih dan bidara untuk memudahkan untuk dalam tahapan uji laboratorium untuk mengetahui kandungan materi/bahan konservan tersebut. Metode analisis yang digunakan untuk mengetahui kandungan bahan konservan dalam kajian ini adalah metode destilasi bahan konservan yang sudah dipilih yaitu daun sirih/piper betle dan daun/biji bidara (zizipus mauritiana) untuk kemudian dilakukan uji aktivitas skala lab untuk menentukan kandungan kimia bahan konservan tersebut. Penelitian in bersifat eksperimental untuk mengetahui efektifitas kedua bahan sebagai konservan anti serangga (rayap) dan jamur, dengan melarutkan kedua bahan tersebut dibuat larutan dengan menggunakan bahan pengencer (pelarut) etanol dengan perbandingan $0.5 \%, 1 \%, 3 \%$ dan 5\%. Sampel penelitian sebanyak 10 ekor ekor rayap kayu kering dengan dengan tiga kali pengulangan. Berdasarkan analisa hasil uji lab serta percobaan di lapangan, kemudian ditarik kesimpulan.

\section{Metode Ekstraksi Daun Sirih (Piper Betle) dan Daun Bidara (Zizipus Mauritiana)}

Minyak Sirih (piper betle) yang digunakan untuk diujicobakan pada serangga (rayap) dan jamur pada kajian ini tidak dilakukan pembuatan sendiri, akan tetapi menggunakan minyak yang tersedia di pasaran. Adapun minyak yang digunakan adalah minyak sirih (piper betle) yang diproduksi oleh Etherische. Untuk pengujian di laboratorium untuk mengetahui kandungan senyawa di dalamnya digunakan ekstrak dari daun sirih (piper betle).Untuk membuat ekstrak daun sirih hijau dilakukan langkah pertama yaitu memilih daun sirih yang tidak terlalu muda dan tidak terlalu tua, karena kadar zat aktif yang tinggi terdapat pada daun sirih tersebut (rizal,2009), daun sirih dicuci bersih, ditiriskan dan dicincang sampai halus. Langkah kedua yaitu daun sirih yang telah dicincang kemudian dihaluskan dengan menggunakan blender ditambah air $100 \mathrm{ml}$ dan kemudian dipanaskan dalam panci sekitar 15 menit. Langkah ketiga yaitu dilakukan penyaringan dengan menggunakan kain penyaring setelah air rebusan dingin. Langkah terakhir hasil saringan dimasukkan ke dalam botol. 


\section{Metode Ekstraksi Minyak dari Biji Bidara (Zizipus Mauritiana)}

Bagian Bidara yang digunakan untuk pembuatan minyak ini adalah biji buah bidara, dimana proses pembuatan minyak dilakukan di laboratorium Universitas Islam Indonesia Yogyakarta. Adapun proses pembuatannya menggunakan sistem rebus atau kukus. Proses pembuatannya adalah sebagai berikut.

1. Bïji buah Bidara sebanyak $5 \mathrm{~kg}$ digiling sehingga menjadi halus

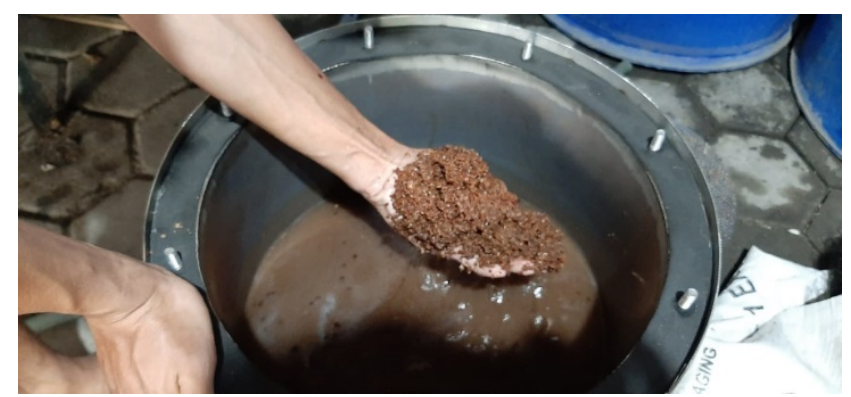

Foto 3. Menghaluskan biji buah bidara

2. Setelah selesai dihaluskan kemudian dimasukkan kedalam ketel penyulingan

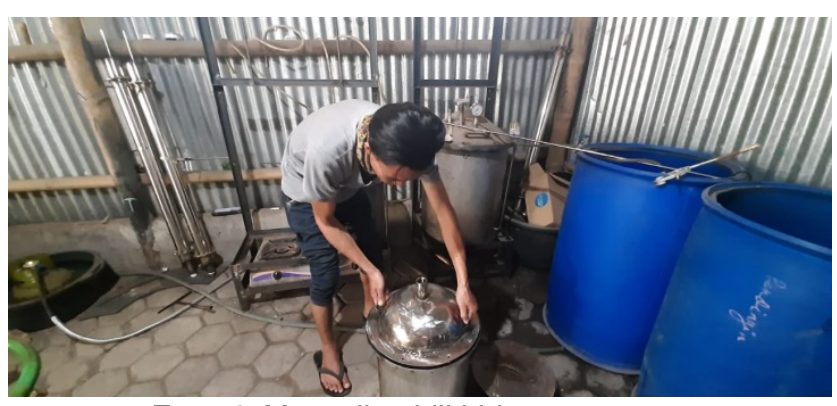

Foto 4. Menyuling biji bidara

3. Jika hasil gilingan terlalu halus, maka ditambahkan ijuk pada proses penyulingan agar hasil gilingan tidak langsung menempel pada ketel (agar bahan tidak gosong)

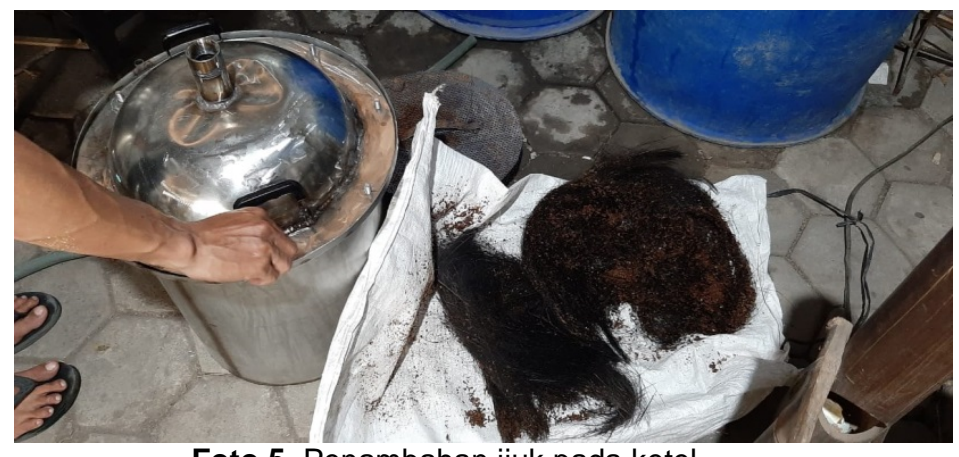

Foto 5. Penambahan ijuk pada ketel 
4. Proses selanjutnya adalah dengan penyulingan selama 4-5 jam

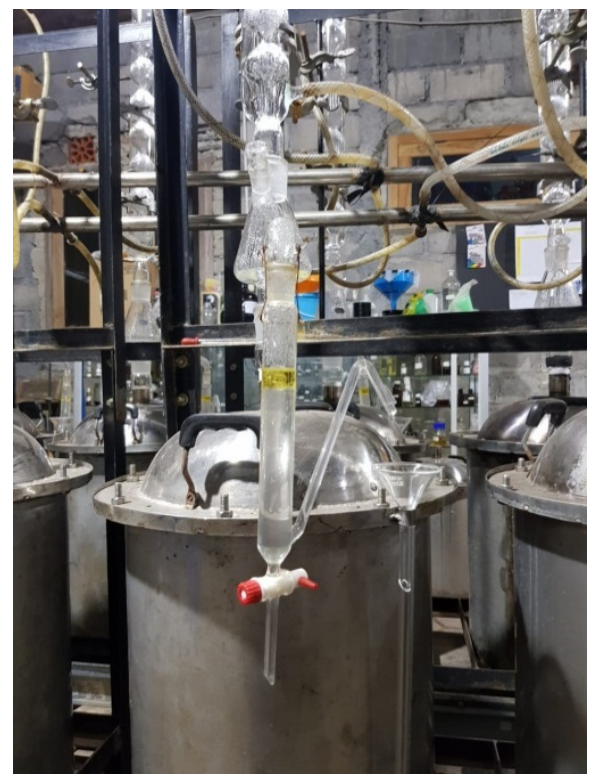

Foto 5. Penyulingan minyak bidara

5. Setelah proses proses destilasi selesai maka dilanjutkan dengan pemisahan antara minyak dengan hidrosolnya

\section{Pembuatan Larutan Minyak Sirih}

Konsentrasi yang digunakan pada pengujian terhadap rayap dan jamur adalah 0,5\%, 1\%, 3\% dan 5\%. Adapun proses pembuatan larutan dengan konsentrasi tersebut diatas adalah persiapan minyak sirih (piper betle) dengan kadar 100\% yang kemudian dilakukan pengenceran dengan pelarut ethanol hingga volume sesuai dengan kebutuhan. Adapun tabel kebutuhan bahan sesuai dengan konsentrasi yang akan diaplikasikan adalah sebagai berikut.

Tabel 2. Tabel kebutuhan minyak sirih (piper betle) sesuai dengan konsentrasi

\begin{tabular}{cccc}
\hline No & Konsentrasi Larutan & Volume minyak sirih yang diambil & Volume Total \\
\hline 1 & $0,5 \%$ & 0,05 gram & 10 gram \\
2 & $1 \%$ & 0,1 gram & $10 \mathrm{gram}$ \\
3 & $3 \%$ & $0,3 \mathrm{gram}$ & $10 \mathrm{gram}$ \\
4 & $5 \%$ & $0,5 \mathrm{gram}$ & $10 \mathrm{gram}$ \\
\hline
\end{tabular}

\section{Pembuatan larutan minyak Bidara}

Pada proses ekstrasi sampai proses penyulingan biji bidara sebanyak $5 \mathrm{~kg}$ hanya mampu mendapatkan minyak sebanyak $2 \mathrm{ml}$. Hal ini sangat mempengaruhi dalam proses pengujian karena keterbatasan bahan. Larutan biji buah bidara yang digunakan dalam pengujian adalah $1 \%, 3 \%$, dan $5 \%$. Adapun Tabel kebutuhan bahan yang digunakan untuk membuat konsentrasi tersebut adalah sebagai berikut. 
Tabel 3. Kebutuhan minyak Bidara (Ziziper Mauritia) sesuai dengan konsentrasi

\begin{tabular}{cccc}
\hline No & Konsentrasi Larutan & $\begin{array}{c}\text { Volume minyak bidara yang } \\
\text { diambil }\end{array}$ & Volume Total \\
\hline 1 & $1 \%$ & $0,1 \mathrm{gram}$ & $10 \mathrm{gram}$ \\
2 & $3 \%$ & $0,3 \mathrm{gram}$ & $10 \mathrm{gram}$ \\
3 & $5 \%$ & $0,5 \mathrm{gram}$ & $10 \mathrm{ram}$ \\
\hline
\end{tabular}

\section{Larutan Hidrosol atau limbah Penyulingan}

Hidrosol merupakan limbah penyulingan yang sedikit banyak masih mengandung minyak atsiri terutama dari golongan fraksi berat (titik didih tinggi). Dalam limbah tersebut diperkirakan masih mengandung senyawa volatil dan non-volatil seperti terpen-terpen yang dapat digunakan. Sama seperti pada pembuatan larutan uji pada minyak sirih dan minyak biji bidara di atas. Adapun pelarut yang digunakan untuk pengenceran adalah menggunakan aquadest. Pembuatan konsentrasi Hidrosol dapat dilihat dalam tabel berikut ini.

Tabel 4. Kebutuhan larutan hidrosol sesuai dengan konsentrasi

\begin{tabular}{cccc}
\hline No & Konsentrasi Larutan & Volume hidrosol yang diambil & Volume Total \\
\hline 1 & $1 \%$ & $1 \mathrm{gram}$ & $100 \mathrm{gram}$ \\
2 & $3 \%$ & $3 \mathrm{gram}$ & $100 \mathrm{gram}$ \\
3 & $5 \%$ & $5 \mathrm{gram}$ & $100 \mathrm{gram}$ \\
4 & $10 \%$ & $10 \mathrm{gram}$ & $100 \mathrm{gram}$ \\
5 & $50 \%$ & $50 \mathrm{gram}$ & $100 \mathrm{gram}$ \\
\hline
\end{tabular}

\section{Persiapan Media Uji pada jamur}

Guna mengetahui efektivitas kedua bahan konservan tersebut terhadap jamur, maka perlu menyiapkan medium CDA (Czapex Dox Agar) yang dimasukkan ke dalam cawan petri sebelumnya disterilkan dengan autoclave pada suhu $1210 \mathrm{C}$ tekanan $1 \mathrm{~atm}$ selama 15 menit. Cawan petri tersebut di biarkan berapa menit hingga agak hangat lalu ditanam dengan isolat jamur yang sudah biakan murni. Penanaman jamur pada cawan petri berisi medium CDA ini dilakukan dalam alat LAF (Laminar Air Flow). Masing-masing cawan petri diberi kertas saring steril yang sudah diberi perlakuan menggunakan minyak uji dan direndam selama 15-20 menit sesuai kadar yang dibutuhkan baik dari minyak atsiri daun Sirih, minyak atsiri Bidara maupun hidrosol buah Bidara selanjutnya cawan petri yang sudah diberi perlakuan di inkubasikan ke dalam inkubator untuk proses inkubasinya.

\section{HASIL UJI BAHAN DAN EFEKTIVITASNYA TERHADAP RAYAP}

Dua sampel bahan untuk diuji sebagai bahan konservan anti serangga yang diambil dari naskah kuna mempunyai kandungan sebagai berikut.

\section{Sirih (Piper Betle)}

Sirih adalah tanaman asli Indonesia yang tumbuh merambat atau bersandar pada batang pohon lain. Dalam budaya di nusantara, daun dan buahnya biasa dikunyah bersama gambir, pinang, tembakau sebagai tradisi makan sirih (nginang/Jawa). Tanaman merambat ini bisa mencapai tinggi $15 \mathrm{~m}$. Batang sirih berwarna coklat kehijauan,berbentuk bulat, 
beruas dan merupakan tempat keluarnya akar. Daunnya yang tunggal berbentuk jantung, berujung runcing, tumbuh berselang-seling, bertangkai, dan mengeluarkan bau yang sedap bila diremas. Panjangnya sekitar $5-8 \mathrm{~cm}$ dan lebar $2-5 \mathrm{~cm}$. Bunganya majemuk berbentuk bulir dan terdapat daun pelindung $\pm 1 \mathrm{~mm}$ berbentuk bulat panjang. Pada bulir jantan panjangnya sekitar 1,5 - $3 \mathrm{~cm}$ dan terdapat dua benang sari yang pendek sedang pada bulir betina panjangnya sekitar 1,5 - $6 \mathrm{~cm}$ dimana terdapat kepala putik tiga sampai lima buah berwarna putih dan hijau kekuningan. Buahnya buah buni berbentuk bulat berwarna hijau keabu-abuan. Akarnya tunggang, bulat dan berwarna coklat kekuningan (Mursito, 2002)

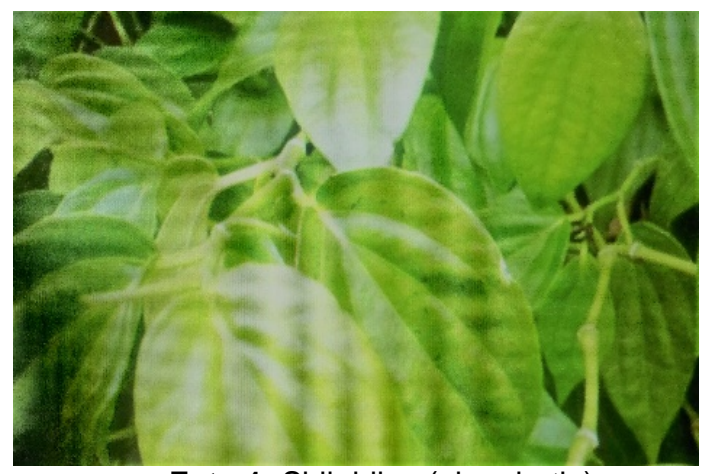

Foto 1. Sirih hijau (piper betle) Foto: penulis

\section{Hasil Analisis HPLC dan GC-MS Sirih (Piper Betle)}

Hasil ekstrak daun sirih kemudian dilakukan analisis menggunakan metode fotokimia (HPLC) dimana tujuan dari analisis ini untuk mengetahui apakah didalam ekstrak sirih yang ada mengandung senyawa-senyawa antiserangga dalam kaitannya dengan kajian yang dilakukan. Kromatografi cair kinerja tinggi (HPLC) adalah tipe kromatografi cair digunakan untuk memisahkan dan mengukur senyawa yang telah dilarutkan dalam larutan. Berdasarkan hasil analisis dengan menggunakan metode HPLC menunjukkan bahwa dalam larutan ekstrak sirih mengandung beberapa senyawa antara lain flavaniod, alkaloid, saponin dan polifenol (lab UII, 2019). Kandungan kimia dari daun sirih hijau (piper batle) dengan metode GC-MS menunjukkan bahwa ekstrak sirih hijau (piper betle) mempunyai tiga puluh satu senyawa yang komponen utamanya yaitu eugenol (25.03\%); asam 2,5-dimetilbenzoat (12.08\%); dekahidro-4a-metil-1-metilenyl naftalena (7.18\%); 1,2,3,4,4a,5,6,8a-oktahidro-7-metil naftalena (8.36\%); dan 1,2,3,4, 4a,5,6,8a-oktahidro-4ametilnaftalena (13.43\%). Hasil ini menunjukkan bahwa mayoritas senyawa aktif dari ekstrak sirih hijau adalah golongan fenolik yang mempunyai aktivitas antibakteri. Senyawa-senyawa yang ada pada tumbuhan dalam hal ini khususnya pada daun sirih mempunyai fungsi insektisida diantaranya golongan sianida, saponin, tanin, flavonoid, alkaloid, steroid dan minyak atsiri (Naria, 2005). Saponin yang terdapat pada tumbuhan berfungsi sebagai pertahanan diri dari serangga dengan menurunkan aktivitas enzim pencernaan dan penyerapan makanan. Flavonoid merupakan senyawa pertahanan tumbuhan yang bersifat menghambat makan serangga dan toksis (Dinata, 2009). Alkaloid mengganggu sistem kerja saraf larva dengan menghambat kerja enzim asetilkolinerase (Cania \& Endar, 2013).

\section{Bidara (Zizipus Mauritiana)}

Bidara atau widara (Ziziphus Mauritiana) adalah sejenis pohon kecil yang menghasilkan buah berukuran kecil yang tumbuh di daerah kering. Tanaman ini dikenal dengan bermacam nama daerah seperti widara (Jawa); bukol (Madura); bekul (Bali). 
Tanaman Bidara berbentuk perdu atau pohon kecil, biasanya bengkok, tinggi hingga 15 meter dan lingkar batang hingga $40 \mathrm{~cm}$. Cabang-cabang menyebar dan terkadang menjuntai, dengan ranting-ranting tumbuh simpang siur dan berambut pendek. Selalu hijau atau semi menggugurkan daun. Daun-daun penumpu berupa duri, sendirian dan lurus (5$7 \mathrm{~mm}$ ), atau berbentuk pasangan dimorfis, di mana yang kedua lebih pendek dan melengkung, kadang-kadang tanpa duri, berdaun tunggal terletak berseling. Helai daun bundar telur menjorong atau jorong lonjong, $2-9 \mathrm{~cm} \times 1.5-5 \mathrm{~cm}$; bertepi rata atau sedikit menginggit; gundul dan mengkilap di sisi atas, dan rapat berambut kempa keputihan di sisi bawahnya; dengan tiga tulang daun utama yang tampak jelas membujur sejajar; bertangkai pendek 8-15 mm (Heyne, K, 1987)

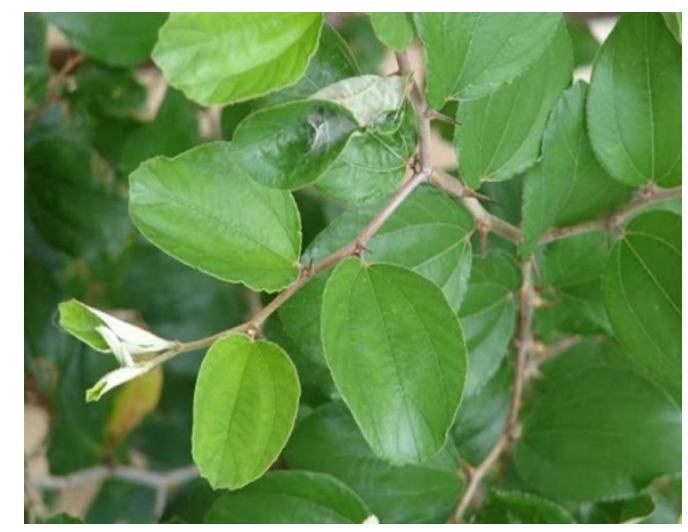

Foto 2. Daun bidara (Sumber: Harman T)

Perbungaan berbentuk paying menggarpu tumbuh di ketiak daun, panjang $1-2 \mathrm{~cm}$, berisi 7-20 kuntum. Berbunga berukuran kecil, bergaris tengah antara 2-3 mm, kekuningan, sedikit harum, bertangkai $3-8 \mathrm{~mm}$; kelopak bertaju 5 bentuk delta (menyegitiga), berambut di luarnya dan gundul di sisi dalam; mahkota 5, agak seperti sudip, cekung dan melengkung. Buah berbentuk bulat hingga bulat telur, hingga $6 \mathrm{~cm} \times 4 \mathrm{~cm}$ pada kultivar-kultivar yang dibudidayakan, tetapi kebanyakan berukuran jauh lebih kecil pada pohon-pohon yang meliar; berkulit halus atau kasar, mengkilap, tipis namun liat, kekuningan, kemerahan hingga kehitaman jika masak; daging buahnya putih, mengeripik, dengan banyak sari buah yang agak masam hingga manis rasanya, menjadi menepung pada buah yang matang penuh. Biji terlindung dalam tempurung yang berbingkul dan beralur tak teratur, berisi 1-2 inti biji yang coklat bentuk jorong (ibid)

\section{Hasil analisis Minyak Biji Bidara}

Analisis Minyak Bidara dilakukan di Laboratium Terpadu Universitas Islam Indonesia dengan menggunakan GC-MS. Adapun dari hasil pengujian adalah sebagai berikut. 


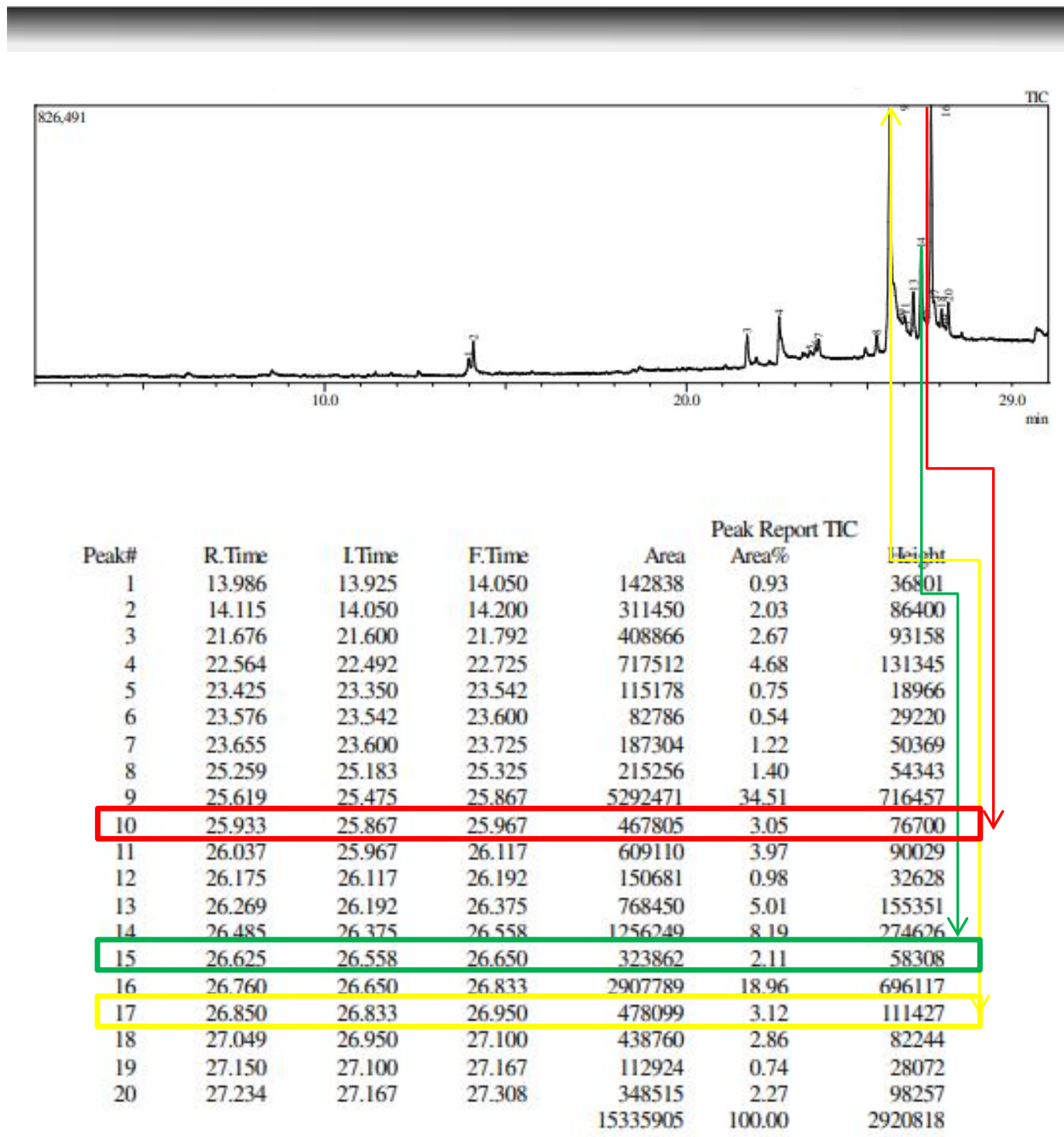

\section{Hasil analisis GC-MS Bidara}

Hasil analisis dengan menggunakan GC-MS menunjukkan bahwa terdapat 20 jenis senyawa dalam minyak buah bidara dengan mencapai peak area 100\%. Adapun senyawasenyawa yang dominan dapat dilihat dalam tabel dibawah ini.

Tabel 5. Senyawa yang terkandung dalam minyak bidara

\begin{tabular}{|c|c|c|c|c|}
\hline No & Peak & Nama Senyawa & Area \% & Keterangan \\
\hline 1 & 9 & $\begin{array}{c}\text { 9-Octadecenoic acid (Z)-, 2,3- } \\
\text { dihydroxypropyl ester (CAS) 1- } \\
\text { Monoolein } \\
\text { Aldo MO } \\
\text { Aldo }\end{array}$ & $34,51 \%$ & \\
& & $\begin{array}{c}\text { Olein, 1-mono- } \\
\text { 1-Oleylglycerol, Mono }\end{array}$ & & \\
\hline 2 & 16 & $\begin{array}{c}\text { Octanoic acid, 1,2,3- } \\
\text { propanetriyl ester (CAS) }\end{array}$ & $18,96 \%$ & $\begin{array}{c}\text { Trioctanoin adalah } \\
\text { trigliserida yang diperoleh }\end{array}$ \\
\hline
\end{tabular}




\begin{tabular}{|c|c|c|c|c|}
\hline & & $\begin{array}{c}\text { Glyceryl trioctanoate } \\
\text { RATO } \\
\text { Trioctanoin } \\
\text { Caprylin, Tricaprylin, Octanoin, } \\
\text { tri, Trioctan }\end{array}$ & & $\begin{array}{l}\text { dengan asilasi tiga gugus } \\
\text { hidroksi gliserol oleh asam } \\
\text { oktanoat. memiliki peran } \\
\text { sebagai antikonvulsan dan } \\
\text { metabolit tanaman. } \\
\text { mengsndung trigliserida dan } \\
\text { ester oktanoat. }\end{array}$ \\
\hline 3 & 14 & $\begin{array}{c}\text { ISO BUTYL LAURATE } \\
\text { ISO BUTYL DODECANOATE }\end{array}$ & $8,19 \%$ & \\
\hline 4 & 13 & THIOGERANIOL & $5,01 \%$ & \\
\hline 5 & 4 & $\begin{array}{l}\text { Hexadecanoic acid, 2-hydroxy- } \\
\text { 1-(hydroxymethyl)ethyl ester } \\
\text { (CAS) 2-Monopalmitin }\end{array}$ & 4,68 & \\
\hline
\end{tabular}

\section{Hasil analisis Hidrosol sisa penyulingan biji / buah bidara}

Selain Minyak Buah Bidara juga dilakukan pengujian hidrosol minyak buah Bidara menggunakan instrument GC-MS. Pengujian ini dilakukan di Laboratorium Terpadu Universitas Islam Indonesia. Adapun hasil analisisnya adalah sebagai berikut.

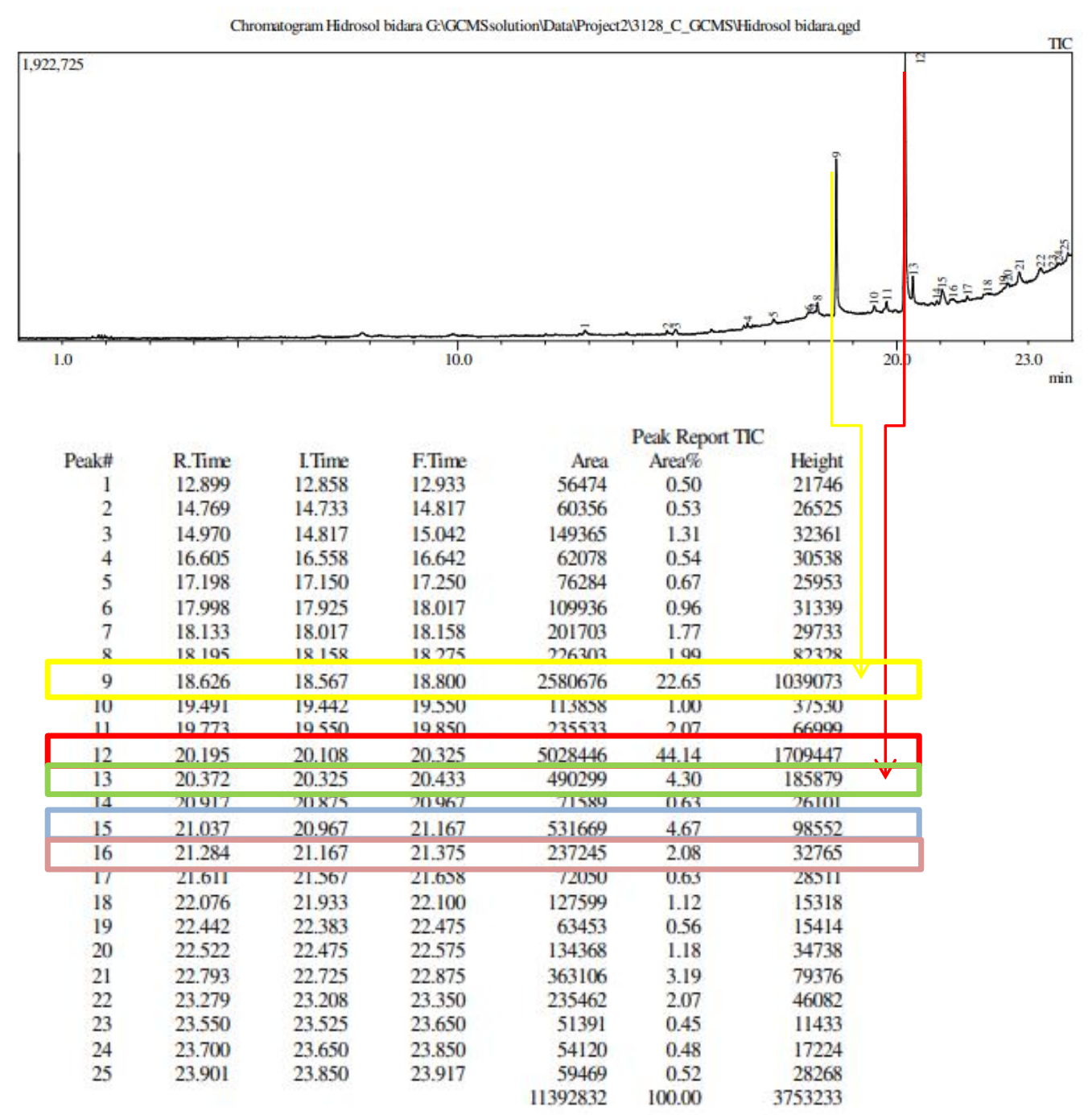




\section{Hasil Uji Efektivitas Tehadap Serangga (Rayap)}

Sebelum melakukan pengujian dilakukan persiapan bahan dan alat. Adapun media yang digunakan adalah cup minum plastik dan kertas saring yang telah digunting melingkar., dengan diameter kertas saring disesuaikan dengan luas permukaan cup plastik. Untuk masing-masing cup menggunakan 2 kertas saring sebagai alas dan sebagai penutup. Sebelum menempatkan rayap pada media, kertas saring diaplikasi bahan terlebih dahulu dengan menggunakan larutan-larutan yan telah dibuat sebelumnya, dan ditunggu sampai kering. Setelah semua kertas saring diaplikasi oleh bahan uji, rayap dimasukkan kedalam cup plastic. Dalam percobaan ini masing-masing cup diberi 10 ekor rayap dan pengamatan dilakukan tiap 24 jam. Masing-masing konsentrasi larutan dilakukan pengulangan 3 kali, kecuali untuk kontrol dan blangko. Cup Kontrol didalamnya hanya memakai kertas saring tanpa aplikasi bahan, sedangkan cup Blangko bersisi kertas saring yang telah diaplikasi dengan pelarut etanol. Uji efektifitas daun/biji bidara terhadap rayap pada rayap dapat dilihat dalam tabel berikut.

Tabel 6. Pengujian dengan Minyak Buah Bidara 1\%, 3\% dan 5\%

\begin{tabular}{|c|c|c|c|c|c|c|c|c|c|c|c|}
\hline \multirow{3}{*}{ No } & \multirow{3}{*}{$\begin{array}{c}\text { Waktu } \\
\text { (hari) }\end{array}$} & \multicolumn{9}{|c|}{ Pengulangan } & \multirow[t]{3}{*}{ Keterangan } \\
\hline & & \multicolumn{3}{|c|}{ BB $1 \%$} & \multicolumn{3}{|c|}{ BB 3\% } & \multicolumn{3}{|c|}{ BB $5 \%$} & \\
\hline & & 1 & 2 & 3 & 1 & 2 & 3 & 1 & 2 & 3 & \\
\hline 1 & Hari ke 1 & 10 & 10 & 10 & 10 & 10 & 10 & 10 & 10 & 10 & \\
\hline 2 & Hari ke 2 & 10 & 10 & 10 & 10 & 10 & 10 & 10 & 10 & 10 & \\
\hline 3 & Hari ke 3 & 10 & 10 & 10 & 10 & 10 & 10 & 10 & 10 & 10 & \\
\hline 4 & Hari ke 4 & 10 & 10 & 10 & 10 & 10 & 10 & 10 & 10 & 10 & \\
\hline 5 & Hari ke5 & 10 & 10 & 10 & 10 & 10 & 10 & 10 & 10 & 10 & \\
\hline 6 & Hari ke 6 & 10 & 10 & 10 & 10 & 10 & 10 & 10 & 6 & 10 & \\
\hline 7 & Hari ke 7 & 10 & 9 & 10 & 10 & 10 & 10 & 10 & 4 & 10 & \\
\hline 8 & Hari ke 8 & 10 & 9 & 9 & 10 & 10 & 10 & 10 & 4 & 10 & \\
\hline 9 & Hari ke 9 & 10 & 9 & 8 & 10 & 10 & 9 & 10 & 1 & 10 & \\
\hline 10 & Hari ke 10 & 10 & 9 & 8 & 10 & 10 & 9 & 10 & 1 & 10 & \\
\hline 11 & Hari ke 11 & 10 & 9 & 8 & 10 & 10 & 8 & 10 & 1 & 10 & \\
\hline 12 & Hari ke 12 & 10 & 9 & 8 & 10 & 10 & 8 & 10 & 1 & 10 & \\
\hline 13 & Hari ke 13 & 10 & 9 & 7 & 9 & 10 & 8 & 10 & 1 & 10 & \\
\hline 14 & Hari ke 14 & 10 & 9 & 7 & 8 & 10 & 8 & 10 & 1 & 10 & \\
\hline 15 & Hari ke 15 & 10 & 9 & 7 & 8 & 10 & 8 & 10 & 1 & 10 & \\
\hline
\end{tabular}


$\begin{array}{lllllllllll}16 & \text { Hari ke } 16 & 10 & 9 & 7 & 8 & 10 & 7 & 10 & 1 & 10\end{array}$

Grafik 1. Pengujian minyak bidara pada serangga (rayap)

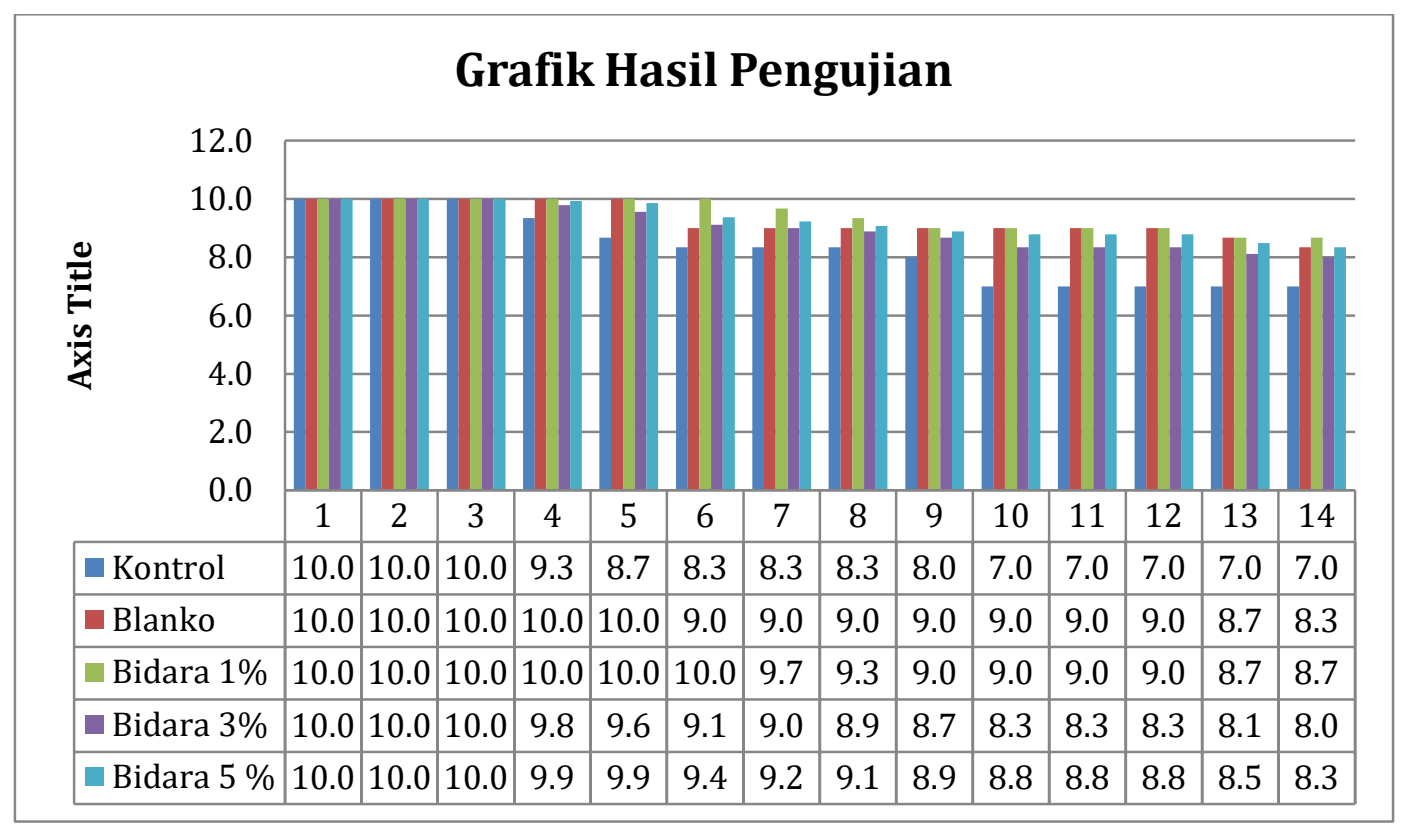

Tabel 7. Pengujian dengan hidrosol

\begin{tabular}{|c|c|c|c|c|c|c|c|c|c|c|c|c|c|c|c|c|c|}
\hline \multirow{3}{*}{ No } & \multirow{3}{*}{$\begin{array}{l}\text { Waktu } \\
\text { (hari) }\end{array}$} & \multicolumn{15}{|c|}{ Konsentrasi } & \multirow{3}{*}{ Keterangan } \\
\hline & & \multicolumn{3}{|c|}{ HB $1 \%$} & \multicolumn{3}{|c|}{ HB $3 \%$} & \multicolumn{3}{|c|}{ HB 5\% } & \multicolumn{3}{|c|}{ HB $10 \%$} & \multicolumn{3}{|c|}{ HB $50 \%$} & \\
\hline & & 1 & 2 & 3 & 1 & 2 & 3 & 1 & 2 & 3 & 1 & 2 & 3 & 1 & 2 & 3 & \\
\hline 1 & $\begin{array}{c}\text { Hari ke } \\
1\end{array}$ & 10 & 10 & 10 & 10 & 10 & 10 & 10 & 9 & 10 & 10 & 9 & 10 & 9 & 10 & 10 & \\
\hline 2 & $\begin{array}{c}\text { Hari ke } \\
2\end{array}$ & 10 & 10 & 10 & 10 & 10 & 10 & 10 & 9 & 10 & 10 & 9 & 10 & 9 & 10 & 10 & \\
\hline 3 & $\begin{array}{c}\text { Hari ke } \\
3\end{array}$ & 10 & 10 & 10 & 10 & 10 & 10 & 8 & 9 & 10 & 10 & 8 & 7 & 8 & 10 & 8 & \\
\hline 4 & $\begin{array}{c}\text { Hari ke } \\
4\end{array}$ & 10 & 10 & 10 & 10 & 10 & 10 & 8 & 9 & 10 & 10 & 7 & 7 & 8 & 10 & 8 & \\
\hline 5 & $\begin{array}{l}\text { Hari } \\
\text { ke5 }\end{array}$ & 10 & 10 & 10 & 10 & 10 & 10 & 8 & 9 & 10 & 10 & 7 & 7 & 8 & 10 & 8 & \\
\hline
\end{tabular}

Percobaan pengujian efektivitas kedua bahan terhadap rayap. Rayap yang diuji ditempatkan pada ruang gelap yaitu pada almari kabinet. dan pengamatan dilakukan setiap 24 jam. Adapun parameter yang dilakukan ada tingkat mortalitas rayap terhadap berbagai macam larutan dengan berbagai konsentrasi. Hasil uji larutan uji terhadap mortalitas rayap dapat dilihat dalam tabel. 
Tabel 8. Data Pengamatan Kontrol

\begin{tabular}{|c|c|c|c|c|c|}
\hline \multirow{2}{*}{ No } & \multirow{2}{*}{$\begin{array}{l}\text { Waktu } \\
\text { (hari) }\end{array}$} & \multicolumn{3}{|c|}{ Pengulangan } & \multirow{2}{*}{ Keterangan } \\
\hline & & K1 & K2 & K3 & \\
\hline 1 & Hari ke 1 & 10 & 10 & 10 & \\
\hline 2 & Hari ke 2 & 10 & 10 & 10 & \\
\hline 3 & Hari ke 3 & 10 & 10 & 10 & \\
\hline 4 & Hari ke 4 & 10 & 10 & 10 & \\
\hline 5 & Hari ke5 & 10 & 10 & 8 & \\
\hline 6 & Hari ke 6 & 10 & 10 & 6 & \\
\hline 7 & Hari ke 7 & 10 & 10 & 5 & \\
\hline 8 & Hari ke 8 & 10 & 10 & 5 & \\
\hline 9 & Hari ke 9 & 10 & 10 & 5 & \\
\hline 10 & Hari ke 10 & 10 & 10 & 4 & \\
\hline 11 & Hari ke 11 & 10 & 10 & 1 & \\
\hline 12 & Hari ke 12 & 10 & 10 & 1 & \\
\hline 13 & Hari ke 13 & 10 & 10 & 1 & \\
\hline 14 & Hari ke 14 & 10 & 10 & 1 & \\
\hline 15 & Hari ke 15 & 10 & 10 & 1 & \\
\hline 16 & Hari ke 16 & 10 & 10 & 1 & \\
\hline
\end{tabular}

Hasil pengamatan selama 16 hari menunjukkan bahwa K1 dan K2 menunjukkan bertahan sampai $100 \%$. Berbeda dengan K3 rayap yang bertahan $10 \%$. Hal ini bisa dipengaruhi oleh beberapa faktor antara lain ukuran rayap yang diambil sebagai sampel pengujian tidak sama ukurannya. Kedua, kondisi kesehatan rayap yang lemah.

Berdasarkan pengamatan pada uji minyak Bidara (Ziziper Mauritania) yang diujikan pada serangga (rayap) dengan konsentrasi 1\%, 3\%, 5\% tidak menunjukkan fungsi sebagai bahan konservan anti serangga terhadap serangga (rayap). Demikian juga dengan hidrosol, berdasarkan hasil pengamatan menunjukkan bahwa larutan hidrosol dengan konsentrasi $1 \%, 3 \%, 5 \%, 10 \%$ dan 50\% belum begitu efektif untuk membunuh rayap. Prosentase serangga (rayap) bertahan hidup masih tinggi mencapai $100 \%$.

Sementara itu pada pengujian minyak sirih $0,5 \%, 1 \%, 3 \%$ dan $5 \%$, dari data hasil pengamatan percobaan rayap terhadap larutan minyak sirih berbagai konsentrasi kurun 5 hari pengamatan, dilakukan pengulangan percobaan. Waktu percobaan pertama adalah berbarengan dengan Kontrol dan Blangko. Pada saat pengamatan 24 jam pertama kadar 1 
\% dan $3 \%$ mempunyai daya bunuh yang lebih besar dari kadar 5\%. Dalam percobaan pengulangan ditambahkan satu konsentrasi lagi yaitu $0,5 \%$.

Tabel 9. Percobaan pengulangan dengan bahan minyak sirih

\begin{tabular}{|c|c|c|c|c|c|c|c|c|c|c|c|c|c|c|}
\hline \multirow{3}{*}{ No } & \multirow{3}{*}{$\begin{array}{c}\text { Waktu } \\
\text { (hari) }\end{array}$} & \multicolumn{12}{|c|}{ Pengulangan } & \multirow{3}{*}{ Keterangan } \\
\hline & & \multicolumn{3}{|c|}{ MS $0,5 \%$} & \multicolumn{3}{|c|}{ MS $1 \%$} & \multicolumn{3}{|c|}{ MS 3\% } & \multicolumn{3}{|c|}{ MS $5 \%$} & \\
\hline & & 1 & 2 & 3 & 1 & 2 & 3 & 1 & 2 & 3 & 1 & 2 & 3 & \\
\hline 1 & Hari ke 1 & 10 & 10 & 10 & 10 & 10 & 10 & 10 & 10 & 10 & 0 & 0 & 0 & \\
\hline 2 & Hari ke 2 & 10 & 10 & 9 & 10 & 10 & 10 & 6 & 9 & 9 & 0 & 0 & 0 & \\
\hline 3 & Hari ke 3 & 10 & 9 & 8 & 10 & 8 & 8 & 4 & 7 & 8 & 0 & 0 & 0 & \\
\hline 4 & Hari ke 4 & 10 & 9 & 8 & 9 & 8 & 7 & 4 & 4 & 7 & 0 & 0 & 0 & \\
\hline 5 & Hari ke5 & 9 & 9 & 8 & 9 & 8 & 4 & 4 & 3 & 3 & 0 & 0 & 0 & \\
\hline
\end{tabular}

Hasil pengamatan 24 jam pertama menunjukkan bahwa rayap pada Minyak sirih konsentrasi 0,5\%-3 \% mempunyai tingkat mortalitas sebesar 40\% - 70 \% sedangkan pada konsentrasi $5 \%$ tingkat mortalitas rayap adalah $100 \%$. Pengaruh minyak sirih terhadap mortalitas rayap sampai dengan hari ke-5 menunjukkan hasil yang terlihat jelas. Dimana semakin tinggi konsentrasi minyak sirih maka daya bunuh terhadap rayap semakin tinggi.

\section{Hasil Pengujian Kuantitatif Efektifitas Antifungal}

Hasil pengujian sementara cawan yang diberi kertas saring dengan perlakuan minyak atsiri dalam inkubator memperlihatkan pada hari ke- 3 dan hari setelahnya dari cawan uji yang menggunakan minyak atsiri Sirih dengan konsentrasi 0,5\%, $1 \%, 3 \%, 5 \%$ tidak terlihat pertumbuhan optimal, sedang pada cawan yang diberi kertas saring dengan perlakuan minyak atsiri bidara dengan konsentrasi $1 \%, 3 \%$ dan $5 \%$ juga tidak terlihat pertumbuhan jamur yang tidak optimal. Sementara itu uji coba menggunakan kertas saring yang diberi perlakuan hidrosol Bidara dengan konsentrasi 1, 3, 5, 10, 50 memperlihatkan hasil tidak menampakkan pertumbuhan.

Perlu dilakukan uji berulang-ulang agar dapat diperoleh hasil yang akurat untuk mengetahui efektivitas minyak bidara (Ziziper Mauritania) dan minyak sirih (piper betle) sebagai bahan alternatif konservasi tradisional anti serangga (rayap). Bahan konservan tradisional yang lain perlu dilakukan uji keilmiahan agar dapat diketahui efektifitasnya sebagai bahan alternatif konservasi tradisional.

\section{KESIMPULAN}

Bahan konservan yang termuat dalam naskah kuna dengan sampel bahan daun bidara dan daun sirih, setelah dilakukan uji laboratorium serta diujikan untuk anti serangga (rayap) dan anti jamur maka dapat diambil kesimpulan bahwa daun dan minyak biji bidara bidara (Ziziper Mauritania) yang diujikan pada serangga (rayap) dengan konsentrasi 1\%, $3 \%, 5 \%$ tidak menunjukkan fungsi sebagai bahan konservan anti serangga. Sementara itu berdasarkan hasil uji aplikasi minyak daun sirih (piper betle) yang diujikan pada serangga (rayap) dengan konsentrasi 1\%, 3\%, 5\% menunjukkan bahwa tingkat mortalitas serangga 
(rayap) pada konsentrasi 1\% - 3\% tingkat mortalitas $40-70 \%$, dan serangga pada konsentrasi $5 \%$ tingkat mortalitas $100 \%$. Kedua bahan tersebut juga diujikan sebagai anti jamur, namun berdasarkan hasil uji kurang menujukkan hasil signifikan sebagai anti jamur, sehingga dari kajian ini dapat disimpulkan minyak sirih dapat menjadi bahan alternatif konservan anti serangga (rayap). 


\section{DAFTAR PUSTAKA}

Ahimsa-Putra, Heddy Shri. 2007. Pemberdayaan Masyarakat Dan Pelestarian Kawasan (Sebuah Sketsa Pemikiran). Disampaikan dalam Bimbingan Teknis Pengelolaan Situs Warisan Dunia, Borobudur 3 - 7 September 2007.

Ambarawati, Dwi Retno Sri. 2009. Kontinuitas Dan Perubahan Vastusatra Pada Bangunan Joglo Yogyakarta. Yogyakarta: Institut Seni Indonesia Yogyakarta.

Ardiyansyah, Panggah. 2019. "Analisis Nilai Penting Situs-Situs di Kawasan Cagar Budaya Borobudur". Borobudur Vol. 13 Nomor 1 Juni 2019 Hal 55-82.

Aryanto, Rudy, So, Gautama Idris. 2012. "Perencanaan Manajemen Lanskap Zonasi Destinasi Wisata Budaya Kota Tua Jakarta”. Binus Business Review Vol. 3 No. 2 November 2012: 973-982. 